\title{
Hepatitis C among former athletes: association with the use of injectable stimulants in the past
}

\author{
Afonso Dinis Costa Passos $/{ }^{+}$, José Fernando de Castro Figueiredo', \\ Ana de Lourdes Candolo Martinelli', Marcia Villanova', Margarida Maria Pásseri do Nascimento', \\ Marie Secaf'
}

Departamento de Medicina Social, Faculdade de Medicina de Ribeirão Preto ${ }^{1}$ Departamento de Clínica Médica, Universidade de São Paulo, Av. Bandeirantes 3900, 14049-900 Ribeirão Preto, SP, Brasil

This study was performed with the purpose of testing the hypothesis that the high prevalence of hepatitis C among former athletes is associated with their past use of injectable stimulants. The study involved the participation of 208 former professional and amateur soccer and basketball players from the region of Ribeirão Preto, Brazil, who answered a questionnaire regarding their exposure to risk factors, including the use of injectable stimulants in the time they were engaged in sporting activities. ELISA tests were used to detect infection by the hepatitis $C$ virus, and confirmed with PCR and genotyping for the positive cases. It was observed that the former use of injectable stimulants was a practice disseminated among the participants (24.5\%), reaching 50.8\% in the professionals. The overall prevalence for hepatitis $C$ was $7.2 \%$, with values of $11 \%$ among professionals and $5.5 \%$ among amateurs. In both categories, the presence of infection was markedly higher among those who admitted past use of injectable stimulants when compared to those who denied such practice (36\% and $0.8 \%$ among amateurs; $21.9 \%$ and $0 \%$ among professionals, respectively). Multivariate analysis showed that the use of those substances was the only variable associated with the risk of hepatitis $C$. This confirms previous observations, performed with reduced sample sizes and without comparison groups, which indicated that the use of injectable vitamins was a risk factor of hepatitis $C$ among former athletes.

Keywords: hepatitis C - former athletes - injectable stimulants

Recently, observations at outpatient clinics have suggested the probability of a higher risk of infection by the hepatitis $\mathrm{B}$ and $\mathrm{C}$ viruses, particularly the latter, among former athletes that practiced their activities between 1950-1980. These observations are in accordance with sparse reports in the literature that pointed at a more frequent distribution of hepatitis $\mathrm{C}$ among former athletes (Paraná et al. 1999, Souto et al. 2003). In an attempt to explain this finding, a hypothesis was formulated: that the use of injectable vitamin complexes and stimulants - a practice reported as common by individuals engaged in sporting activities some decades ago - could be accountable for the dissemination of the hepatitis $\mathrm{C}$ virus (HCV), since the use of contaminated syringes and needles is one of the main known means of transmission of this agent (Heintges \& Wands 1997, Shepard et al. 2005).

Verifying this hypothesis in an important public health issue considering it could identify a new risk group for hepatitis $\mathrm{C}$ and would allow for improved focus on this specific group. In the individual, it would lead

Financial support: CNPq, FAEPA-USP

+ Corresponding author: apassos@fmrp.usp.br

Received 16 July 2008

Accepted 26 November 2008 to a change in medical practice in terms of anamnesis, since it would force the inclusion of questions regarding the former use of licit injections when practicing sports, an issue not considered relevant today.

Nevertheless, the hypothesis of hepatitis $\mathrm{C}$ being associated with the former use of injectable stimulants has never been appropriately researched in previous reports based on descriptive studies, a small number of participants, and without comparison groups. Thus, the need for a deeper investigation of the issue emerged. This study has the general objective of characterizing former athletes who practiced sporting activities between 1960-1985 in the region of Ribeirão Preto and Franca, state of São Paulo, Brazil, in terms of $\mathrm{HCV}$ infection and risk factor antecedents, particularly the use of injectable stimulants.

\section{SUBJETCS, MATERIALS AND METHODS}

An active search was performed for former soccer and basketball players who were engaged in sporting activities in the region of Ribeirão Preto, as professionals or amateurs, between 1960-1985. The initial subject was a former internationally acknowledged soccer player, who is also a physician and lives in Ribeirão Preto. His participation made it easier for the researchers to make contact with former athletes of his generation. Participants were contacted either individually, after their identification and scheduling a meeting, or through visits at night or on weekends to places where former athletes meet to play their traditional recreational matches. Starting with the identification of one or a group of former 
athletes, based on their indications of other fellows, the next step was to locate other potentially eligible individuals, always using an active search strategy.

In every occasion, the study objectives and methodology were explained to the potential participants, along with information about the essential health issues involving viral hepatitis, such as transmission mechanisms, evolution, complications, treatment possibilities and the benefits of being diagnosed. The people who met the inclusion criteria and formally agreed to participate in the study, recorded by signing a free and informed consent form provided a $10 \mathrm{~mL}$ blood sample, which was collected by vein puncture using disposable materials. At the same time, a specific questionnaire was individually administered to obtain demographic data, information about their exposure to injectable vitamin complexes during the period they were engaged in sporting activities and risk factors for viral hepatitis, particularly the one caused by virus $\mathrm{C}$. The blood samples were taken to the Serology Laboratory of the Clinic Hospital of the Ribeirão Preto Medical School where they were submitted to centrifugation and stored at $-20^{\circ} \mathrm{C}$. After completing the collection, the samples were submitted to immunoenzyme tests for Hepatitis C (anti-HCV: AxSYM HCV 3.0, Abbott, Wiesbaden, Germany).

The anti-HCV positive samples were submitted to HCV RNA detection by PCR (Cobas Amplicor; Roche, Manheim, Germany) and genotyping by a line probe assay (HCV Genotype assay, LiPA; Versant, Bayer, Tarrytown, NY, USA). The assays and interpretation of the results were performed following the manufacturers' recommendations. The statistical analysis was performed by applying the log-binomial model (Skov et al. 1998), first testing the association between each possible independent variable and the presence of hepatitis C. The variables that show a $p$ value smaller or equal to 0.20 were submitted to a multivariate analysis, also using the log-binomial model.

The project was approved by the Research Ethics Committee of the Clinic Hospital of the Ribeirão Preto Medical School and data collection was performed between 2004-2007.

\section{RESULTS}

Of the 208 participants, the great majority (200) consisted of former professional and amateur soccer players. The average age was 47.1 years, ranging from 37-76 years. Table I shows the following findings:

About $25 \%$ of participants (51) reported using injectable vitamin complexes/stimulants in the past, during the period they were engaged in sporting activities. Of these, $32(50.8 \%)$ were professionals and $19(13.1 \%)$ were amateurs $(\mathrm{p}<0.0001)$.

The overall positivity for infection by the $\mathrm{HCV}$ reached $7.2 \%$ (CI 95\%: 3.7-10.7) with values of $11.1 \%$ among professionals (CI 95\%: 3.4-18.9) and 5.5\% among amateurs (CI 95\%: 1.8-9.2). This difference was not considered significant from a statistical point of view $(p=0.157)$.

A great difference was observed in hepatitis $\mathrm{C}$ positives among those who used injectable stimulants (14 or $27.5 \%)$ and those who did not (1 or $0.6 \%$ ). The statistical analysis revealed a strong association between the variables $(\mathrm{p}<0.0001)$. These evident differences were present in both the professionals ( $21.9 \%$ and $0 \%$, respectively) and amateurs (36.8\% and $0.8 \%$, respectively).

Although a higher prevalence of hepatitis $\mathrm{C}$ was observed among former athletes older than 40 years (compared to younger ones) and those with over 10 years of sporting practice, there were no associations between those variables and a positive infection reported at the level of $5 \%$ ( $\mathrm{p}$ values of 0.102 and 0.199 , respectively).

The variables using injectable stimulants, professional category, age and time of sporting practice were submitted to a multivariate analysis through the application of the log-binomial model. The result is shown in Table II which shows that former use of injectable stimulants was the only variable shown to be an independent predictor of the risk of developing hepatitis $\mathrm{C}$ in the studied population.

Twelve HCV RNA positive samples were genotyped as genotype 1 , subtypes $1 \mathrm{a}(\mathrm{n}=5)$ and $1 \mathrm{~b}(\mathrm{n}=7)$ and three samples were genotype 3 , subtype $3 \mathrm{a}$.

\section{DISCUSSION}

The supposition that the high number of hepatitis $\mathrm{C}$ cases currently observed among individuals that were

TABLE I

Participants according to their category, use of injectable stimulants and positivity for hepatitis $\mathrm{C}$ among former athletes from Ribeirão Preto, state of São Paulo, Brazil, and region, 2008

\begin{tabular}{|c|c|c|c|c|c|c|c|c|}
\hline \multicolumn{2}{|c|}{ Hepatitis C } & \multicolumn{2}{|c|}{ Positive } & \multicolumn{2}{|c|}{ Negative } & \multicolumn{2}{|c|}{ Total } & \multirow[b]{2}{*}{$\mathrm{p}$} \\
\hline Category & Stimulants & $\mathrm{n}$ & $\%$ & $\mathrm{n}$ & $\%$ & $\mathrm{n}$ & $\%$ & \\
\hline \multirow[t]{3}{*}{ Professionals } & Yes & 7 & 21.9 & 25 & 78.1 & 32 & 100.0 & \\
\hline & No & - & - & 31 & 100.0 & 31 & 100.0 & 0.01 \\
\hline & & 7 & 11.1 & 56 & 88.9 & 63 & 100.0 & \\
\hline \multirow[t]{3}{*}{ Amateurs } & Yes & 7 & 36.8 & 12 & 63.2 & 19 & 100.0 & \\
\hline & No & 1 & 0.8 & 125 & 99.2 & 126 & 100.0 & $<0.01$ \\
\hline & & 8 & 5.5 & 137 & 94.5 & 145 & 100.0 & \\
\hline Total & & 15 & 7.2 & 193 & 92.8 & 208 & 100.0 & \\
\hline
\end{tabular}


TABLE II

Multivariate analysis results through the log-binomial model, applied on former athletes from Ribeirão Preto, São Paulo, Brazil, and region, 2008

\begin{tabular}{lccc}
\hline Variable & Prevalence ratio & Confidence interval (95\%) & $\mathrm{p}$ \\
\hline Use of injectable stimulants $^{a}$ & 1.3276 & $1.2223-1.4420$ & $<0.0001$ \\
Professionals x amateurs $^{b}$ & 0.9691 & $0.8949-1.0494$ & 0.440 \\
Age $^{c}$ & 1.0044 & $0.9403-1.0729$ & 0.896 \\
Time of sporting activity $^{d}$ & 1.0687 & $0.9855-1.1589$ & 0.108 \\
\hline
\end{tabular}

$a$ : 1: yes, 0 : no; $b$ : 1 : professional, 0 : amateur; $c$ : 1 : more than 40 years, 0 : less than 40 years; $d: 1:$ more than 10 years, $0:$ less than 10 years.

once engaged in sporting activities could be associated with the use of injectable substances, with the purpose to increase their performance, emerged back in 1999, with the description of three cases of infection in former amateur soccer players in the state of Bahia (Paraná et al. 1999). Later, in 2003, there was a report about three positive cases among 40 former soccer players from the state of Mato Grosso, all having used injectable stimulants in the past (Souto et al. 2003). In 2006, a news report published in the Folha de São Paulo newspaper (Roseguini 2006) reported that seven former members of the Próspera team, from the city of Criciúma (state of Santa Catarina), died due to complications caused by hepatitis $\mathrm{C}$, in addition to others who were infected. Despite the one possible association, all these references resulted from descriptive studies, without comparison groups, and with very small sample sizes. As justified in one of the previous studies (Souto et al. 2003), the small number of individuals was due to the difficulties in locating and including potential participants. This problem was also experienced in the present study, as a considerable number of former athletes referred by their friends no longer lived in their original cities and their whereabouts were unknown. An additional factor was that several of them had already passed away, particularly those that were engaged in sporting activities in the 1960s and 1970s. For this reason, the study was spread to seven cities in the region of Ribeirão Preto and included a considerably greater number of participants than in the previous descriptions. The adopted methodology permitted, for the first time, an objective comparison of the risks between individuals with and without previous exposure to injectable substances.

The reported high frequency regarding the use of injectable substances with stimulant properties was remarkable. Even considering the possibility of a bias derived from the denial of its use by some former athletes, approximately one forth reported being exposed. The stated substances were all licit at the time the participants used them. Those substances included glucose, products commercialized under the brand names Tiaminose, Energizan and, especially, Glucoenergan, reported by the vast majority as the most frequently used. This medication has fencamfamine as its base and was developed in the 1960 s as an appetite suppressor. Its use was popular among the athletes of that period. According to the participants' reports, it was administered in the locker room before matches or practice, either by their own initiative or from the masseur or another employee in the club. In a period before disposable syringes and needles appeared, these applications were performed with reusable material, which were submitted to the traditional boiling process between applications, even this minimal decontamination process often did not take place. Additionally, injections were applied subsequently in several individuals, using the same needle and syringe set.

The potential for hepatitis $\mathrm{C}$ transmission by these practices is evidenced by the prevalence of infection observed among the participants, with a global value (7.2\%) considerably more elevated than in the overall population. Moreover, it is evidenced by the astonishing differences between the prevalence observed in those exposed and those not exposed (27.5\% and $0.6 \%$, respectively). These differences are overwhelming between professionals as well as amateurs. After controlling the variables professional category, age and time of sporting practice, the exposure to injectable substances has a predictor role independent of the risk of developing hepatitis $\mathrm{C}$.

Genotype 1 represented $80 \%$ of the positive samples, a percentage above those described for the states of Rio Grande do Sul, Santa Catarina (da Silva et al. 2007) and São Paulo, but similar to that observed in Southeast Brazil (Campioto et al. 2005). This fact can be associated with the study field's proximity to the state of Minas Gerais and the origin of several participants, from this and other states in the Southeast. The occurrence of genotype 3 as the second most frequent is in agreement with findings verified in both Southeast and South Brazil, as well as in the country as a whole (da Silva et al. 2007, Botelho et al. 2008).

The findings of the present study substantially reinforce the association between the use of injectable substances in the past and hepatitis $\mathrm{C}$ among former athletes. This relationship assumes great sanitary importance, as it leads to the identification of a new risk group for hepatitis $\mathrm{C}$ and should direct public health action. Furthermore, it should justify a change in medical practice of patient anamnesis and approach. Until now, it has been common to associate hepatitis $\mathrm{C}$ exclusively with the use of illicit injectable substances and questions regarding the use of common licit injections in the past have been neglected. Based on the evidence collected so 
far, there is a need to incorporate the question of past licit injections in the routine anamnesis of individuals that were engaged in sporting activities from 1960-1985 and individuals that report an antecedent use of injectable stimulants should undergo serologic examination.

\section{REFERENCES}

Botelho SM, Ferreira RC, Reis NRS, Kozlowski AG, Carneiro MAS, Teles AS, Yoshida CFT, Martins RMB 2008. Epidemiological aspects of hepatitis $\mathrm{C}$ virus infection among renal transplant recipients in Central Brazil. Mem Inst Oswaldo Cruz 103: 472-476.

Campioto S, Pinho JRR, Carrilho FJ, da Silva LC, Souto FJD, Spinelli V, Pereira LMMB, Coelho HSM, Silva AO, Fonseca JC, Rosa H, Lacet CMC, Bernardini AP 2005. Geographic distribution of hepatitis C virus genoypes in Brazil. Braz J Med Bio Res 38: 41-49.

Da Silva CMD, Costi C, Krug LP, Ramos AB, Grandi T, Gandolfi VL, Menezes ME, Ocampos M, Niel C, Rossetti MLR 2007. High proportion of hepatitis $\mathrm{C}$ virus 1 and 3 in a large cohort of patients from Southern Brazil. Mem Inst Oswaldo Cruz 102: 867-870.

Heintges T, Wands JR 1997. Hepatitis C virus: epidemiology and transmission. Hepatology 26: 521-526.

Paraná R, Lyra L, Trepó C 1999. Intravenous vitamin complexes used in sporting activities and transmission of $\mathrm{HCV}$ in Brazil. Am J Gastroenterol 94: 857-858.

Roseguini G 2006. Seringas da morte. Folha de São Paulo, Jan 8, Seção D:4.

Shepard CW, Finelli L, Alter MJ 2005. Global epidemiology of hepatitis C virus infection. Lancet Infect Dis 5: 558-567.

Skov T, Deddens J, Petersen MR, Endahl L 1998. Prevalence proportion ratios: estimation and hypothesis testing. Int $J$ Epidemiol 27: 91-95.

Souto FJD, Silva AG, Yonamine F 2003. Risk of hepatitis C among brazilian ex-soccer players. Mem Inst Oswaldo Cruz 98: 1025-1026. 